\title{
An integrative genetic linkage map of winter wheat (Triticum aestivum
}

L.)

\section{Journal Article}

\section{Author(s):}

Paillard, S.; Schnurbusch, T.; Winzeler, M.; Messmer, M.; Sourdille, P.; Abderhalden, Olaf; Keller, B.; Schachermayr, G.

Publication date:

2003-11

Permanent link:

https://doi.org/10.3929/ethz-b-000053327

\section{Rights / license:}

In Copyright - Non-Commercial Use Permitted

\section{Originally published in:}

Theoretical and Applied Genetics 107(7), https://doi.org/10.1007/s00122-003-1361-6 


\section{S. Paillard • T. Schnurbusch • M. Winzeler • \\ M. Messmer • P. Sourdille • O. Abderhalden • \\ B. Keller • G. Schachermayr \\ An integrative genetic linkage map of winter wheat (Triticum aestivum L.)}

Received: 3 March 2003 / Accepted: 11 June 2003 / Published online: 30 July 2003

(C) Springer-Verlag 2003

\begin{abstract}
We constructed a genetic linkage map based on a cross between two Swiss winter wheat (Triticum aestivum L.) varieties, Arina and Forno. Two-hundred and forty $\mathrm{F}_{5}$ single-seed descent (SSD)-derived lines were analysed with 112 restriction fragment length polymorphism (RFLP) anonymous probes, 18 wheat cDNA clones coding for putative stress or defence-related proteins and 179 simple-sequence repeat (SSR) primer-pairs. The 309 markers revealed 396 segregating loci. Linkage analysis defined 27 linkage groups that could all be assigned to chromosomes or chromosome arms. The resulting genetic map comprises 380 loci and spans 3,086 cM with $1,131 \mathrm{cM}$ for the A genome, $920 \mathrm{cM}$ for the B genome and $1,036 \mathrm{cM}$ for the $\mathrm{D}$ genome. Seventeen percent of the loci showed a significant $(P<0.05)$ deviation from a $1: 1$ ratio, most of them in favour of the Arina alleles. This map enabled the mapping of QTLs for resistance against several fungal diseases such as Stagonospora glume blotch, leaf rust and Fusarium head blight. It will also
\end{abstract}

S. Paillard and T. Schnurbusch contributed equally to the work

Communicated by H.C. Becker

S. Paillard · M. Winzeler - G. Schachermayr

Swiss Federal Research Station for Agroecology

and Agriculture (FAL),

Reckenholzstrasse 191, 8046 Zürich, Switzerland

T. Schnurbusch · O. Abderhalden · B. Keller Institute of Plant Biology, University of Zürich, Zollikerstrasse 107, 8008 Zürich, Switzerland

M. Messmer

Pharmaceutical Institute, University of Basel,

Benkenstrasse 254, 4108 Witterswil, Switzerland

P. Sourdille

Institut National de la Recherche Agronomique (INRA), Domaine de Crouelle,

234 rue du Brezet, 63039 Clermont-Ferrand, France

G. Schachermayr (๘)

Indo-Swiss Collaboration in Biotechnology (ISCB),

Institute of Biotechnology, ETH-Hoenggerberg,

8093 Zürich, Switzerland

e-mail: schachermayr@biotech.biol.ethz.ch be very useful for wheat genetic mapping, as it combines RFLP and SSR markers that were previously located on separate maps.

Keywords Triticum aestivum · RFLP · SSR · Genetic linkage map $\cdot$ Segregation distortion

\section{Introduction}

Bread wheat (Triticum aestivum L. em. Thell.) has an allohexaploid genome (AABBDD, $2 n=6 x=42$ ) with seven groups of homoeologous chromosomes. It is one of the most important food crops and the development of genetic maps is essential to better understand the genetics of agronomically important traits in this species. So far, maps of bread wheat were mainly developed from interspecific or wide crosses (Chao et al. 1989; Liu and Tsunewaki 1991; Gale et al. 1995; Messmer et al. 1999). The low level of polymorphism revealed by RFLP markers in wheat (Chao et al. 1989; Liu et al. 1990) has often hampered the establishment of intervarietal genetic linkage maps.

However, the development of such maps is a prerequisite for the dissection of complex agronomic traits through QTL analysis and the use of these QTLs in plant breeding via marker-assisted selection. The first intervarietal map of bread wheat, based on RFLP markers, was published in 1997 (Cadalen et al. 1997). The mapping population consisted of $106 \mathrm{DH}$ lines derived from a cross between Chinese Spring and the French semi-dwarf winter wheat cultivar Courtot. This map contained 266 loci covering $1,772 \mathrm{cM}$ (less than $50 \%$ of the genome). It had a poor representation of the $\mathrm{D}$ genome and no marker was assigned to chromosomes 2D, 4D and 5D. The recent development and mapping of microsatellite markers in wheat (Bryan et al. 1997; Röder et al. 1998; Gupta et al. 2002; Guyomarc'h et al. 2002), as well as the transfer of microsatellites isolated from Aegilops tauschii to bread wheat (Pestsova et al. 2000; Guyomarc'h et al. 2002), facilitates the development and improvement of interva- 
rietal linkage maps in wheat. Microsatellite markers are known to be highly polymorphic in wheat, even between closely related lines (Plaschke et al. 1995). These PCRbased markers are highly suitable for genetic mapping and breeding purposes because they require a low amount of DNA, can be easily automated and allow high-throughput screening, can be exchanged between laboratories and are highly transferable between populations. Using microsatellite markers, Sourdille et al. (2003) increased the coverage of the Courtot $\times$ Chinese Spring genetic map up to more than $90 \%(3,685 \mathrm{cM})$.

The objective of the present study was to construct a genetic linkage map in a recombinant inbred-line population obtained from a cross between two closely related winter wheat varieties, Arina and Forno. This map represents an important tool for QTL analysis of agronomically important traits and has already successfully been used for the QTL mapping of genetic loci involved in resistance against several diseases: Stagonospora glume blotch (Schnurbusch et al. 2003), leaf rust and Fusarium head blight (our unpublished results)

\section{Materials and methods}

Plant material

The population used in this study consisted of $240 \mathrm{~F}_{5}$ recombinant inbred lines (RILs) derived by single-seed descent from a cross between Arina and Forno, two Swiss winter wheat varieties originating from the breeding programs of the Swiss Federal Research Station for Agroecology and Agriculture (FAL, ZürichReckenholz, Switzerland). These varieties were chosen because they have been grown on a considerable acreage in Switzerland and differ for many agronomically important traits as well as for baking quality. Forno, which has been used for wheat production between 1986 and 1997, has a durable resistance against leaf rust, but is highly susceptible to leaf and glume blotch caused by Stagonospora nodorum as well as to Fusarium head blight. Arina has covered more than $40 \%$ of the Swiss wheat acreage since 1985 . This variety has poor resistance against leaf rust but a high level of resistance against $S$. nodorum and a good resistance to Fusarium head blight.

\section{RFLP assay}

RFLP analysis was performed with 479 probes and seven enzymes as described by Messmer et al. (1999). When the information was available, the expected chromosomal location of the polymorphic bands was used as a criterion for the choice of the enzyme (RFLP patterns of psr probes on nulli-tetrasomic lines of Chinese Spring were kindly provided by Dr. M. Gale, John Innes Centre, Norwich, UK).

Three hundred and ninety eight RFLP probes were used as anonymous probes and corresponded to genomic DNA clones from wheat (psr, ptag - Xglk loci-, ksu, wg, tam, fba, fbb, gbx, gbxG, gbxR) and barley (mwg), as well as cDNA clones from barley (bcd) and oat (cdo). They have been previously described by Chao et al. (psr, 1989), Liu and Tsunewaki (ptag, 1991), Gill et al. (ksu, 1991), Heun et al. (bcd, cdo, wg, 1991), Devey and Hart (tam, 1993), Graner et al. (mwg, 1991), Leroy (fba, fbb, 1995) and Mingeot and Jacquemin (gbx, gbxg, gbxr, 1999). One hundred and ninety six probes were polymorphic between the parents and 114 were used for mapping.
Eighty one selected cDNA clones coding for proteins with known or potential functions in stress or defence against pathogens were also tested for polymorphisms between the parental lines. Fifty five out of them corresponded to hexaploid wheat cDNAs, whereas the others originated from barley (13), maize (6), rice (4), sorghum (1), Triticum durum (1) and Triticum monococcum (1). Eighteen polymorphic probes were used for mapping (Table 1).

Microsatellite assay

Three hundred and twenty nine simple sequence repeats (SSR) were used to screen the parental lines: $188 \mathrm{gwm}$ and $25 \mathrm{gdm}$ markers developed at IPK Gatersleben (Institute of Plant Genetics, Germany, Röder et al. 1998; Pestsova et al. 2000), 70 cfd and 25 cfa markers developed at INRA Clermont-Ferrand (France, Guyomarc'h et al. 2002; Sourdille et al. 2003), 21 wmc markers from the Wheat Microsatellite Consortium (Gupta et al. 2002) and one psp marker, psp2999, developed at John Innes Centre (Norwich, UK). One hundred and seventy nine out of 186 polymorphic microsatellites were used for mapping. The polymerase chain reactions (PCR) were performed in 10- $\mu$ l aliquots in a PTC-200 (MJ Research) Peltier 9600 thermal cycler and in a BioRad 9600 thermal cycler. The reaction buffer contained $16.25 \mathrm{ng}$ of template DNA, $0.125 \mathrm{mM}$ of each deoxynucleotide, $10 \mathrm{nM}$ Tris$\mathrm{HCl}(\mathrm{pH} 8.3), 50 \mathrm{mM} \mathrm{KCl}, 1.5 \mathrm{mM} \mathrm{MgCl}_{2}, 0.05 \mu \mathrm{M}$ labelled primer (IRD700 or 800), $0.2 \mu \mathrm{M}$ unlabelled primer and $0.5 \mathrm{U}$ of Taq DNA polymerase (SIGMA). Twenty four to 35 cycles of 1 min at $94{ }^{\circ} \mathrm{C}, 1 \mathrm{~min}$ between 50 to $63{ }^{\circ} \mathrm{C}$ depending on the primer combination and $1 \mathrm{~min}$ at $72{ }^{\circ} \mathrm{C}$ were performed, followed by an elongation step of $10 \mathrm{~min}$ at $72{ }^{\circ} \mathrm{C}$. Fragment analysis was carried out on a LI-COR 4200 DNA analyser. Five microliters of formamide tracking-dye (Amersham) was added per PCR reaction and the reaction was run on $8 \%$ acrylamide gels.

Nullisomic-tetrasomic analysis

A series of nullisomic-tetrasomic (nulli-tetra) lines of Chinese Spring (CS) (Sears 1966) was used to confirm the chromosomal location for 37 RFLP probes and 135 SSR primer pairs.

\section{Data analysis and linkage mapping}

The observed segregation ratios were tested by chi-square analyses (1:1). A segregation distortion region (SDR) was defined by at least three adjacent marker loci showing a significant segregation distortion $(P<0.05)$. The linkage analysis was performed with the computer program MAPMAKER (Lander et al. 1987) for selfed recombinant inbred lines. Recombination frequencies were converted to centiMorgans $(\mathrm{cM})$ using Haldane's mapping function (Haldane 1919) because of the independent cross-over events in different meiotic phases during the development of the population. The linkage groups were constructed using the "two-point/group" command with a LOD threshold of 4.0 and a maximum distance of $30 \mathrm{cM}$.

For each linkage group, the marker order was obtained in several steps. First, a set of markers was selected using the "informativeness criteria" and "suggest subset" commands. The "maximum distance" and "minimum individuals" arguments were respectively set to $4 \mathrm{cM}$ and 200 informative individuals. Markers showing distorted segregations were discarded. The selected markers were ordered using the "compare" command. Additional markers were added afterwards on this frame using the "try" command. Non-distorted markers that could be mapped with a LOD threshold superior to 3.0 were integrated first, followed by markers with a LOD below 3.0 or/and distorted segregation. The final order was verified with the "ripple" command. The groups identified from the same chromosome were linked if the distance was less than $50 \mathrm{cM}$. The "compare" command was used to control the marker order in the regions where the groups were merged, and 


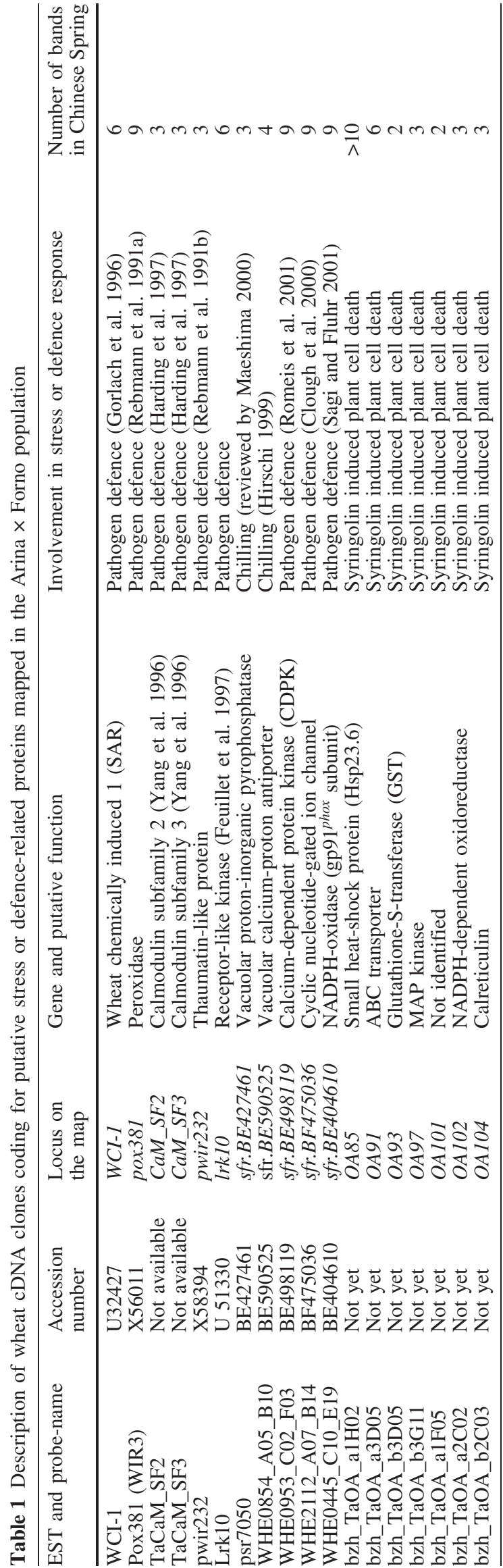

the "ripple" command was used to verify again the order along the whole chromosome. The "graphical genotype" concept (Young and Tanksley 1989) was then used to control the accuracy of the marker order and to identify potential errors. The corresponding data were controlled on the original autoradiograms (RFLPs) or data (SSRs) and corrected if necessary.

The genetic map was finally drawn using the computer program Mapchart Version 2.1 (Voorips 2002). To compare the map with other published maps (ITMI, Röder et al. 1998; Courtot $\times$ Chinese Spring, Sourdille et al. 2003) correlations were calculated on the distances of all common intervals using the SAS statistics package (SAS Institute, Raleigh, N.C.).

\section{Results}

Parental screening using RFLP and microsatellite markers

Out of the 398 anonymous RFLP probes tested on the parental lines Arina and Forno, 387 exhibited a clear banding pattern and $196(51 \%)$ were polymorphic with at least one restriction enzyme. For the 81 probes related to stress or defence response, the level of polymorphism was much lower $(27 \%)$. The clones derived from hexaploid wheat revealed polymorphisms and gave clear patterns, whereas clones originating from barley, maize, rice, sorghum, $T$. durum and T. monococcum showed a high background or were monomorphic. SSR markers revealed a higher level of polymorphism compared to the RFLP probes: 305 out of the 329 primer pairs tested produced amplification products and $186(61 \%)$ of them were polymorphic. Although microsatellites are supposed to be locus specific, several primer pairs amplified more than one fragment. Twenty nine (16\%) of the 179 primer pairs revealed two or three polymorphic loci. The maximal number of polymorphic loci revealed by one marker was six for RFLP probes and three for SSR markers.

\section{Construction of the linkage map}

One hundred and twelve RFLP probes with unknown function, 18 wheat cDNA clones coding for putative stress or defence-related proteins and 179 SSR primer pairs, were used to screen the population. These 309 markers revealed 396 loci (188 RFLPs and 208 SSRs) representing a mean of 1.28 loci per marker (1.43 and 1.16 for RFLP and SSR markers, respectively). Among these loci, 105 showed dominant inheritance $(26.5 \%)$ including 54 RFLP loci (28.7\%) and 51 SSR loci (24.5\%).

After elimination of two extremely distorted loci, the mapping of the 394 remaining loci resulted in 27 linkage groups comprising 3 to 29 loci. Fourteen loci remained unlinked. Each of the linkage groups could be assigned to one of the 21 chromosomes based on analysis for nullitetrasomic lines or information from previous mapping studies. This resulted in a genetic map comprising 380 loci and spanning $3,086 \mathrm{cM}$, with $1,131 \mathrm{cM}(37 \%)$ for the A genome, $920 \mathrm{cM}(30 \%)$ for the B genome and $1,036 \mathrm{cM}$ (33\%) for the D genome (Fig. 1). The chromosome size ranged from $17 \mathrm{cM}$ for chromosome $4 \mathrm{D}$ to $243 \mathrm{cM}$ for 
ลิ
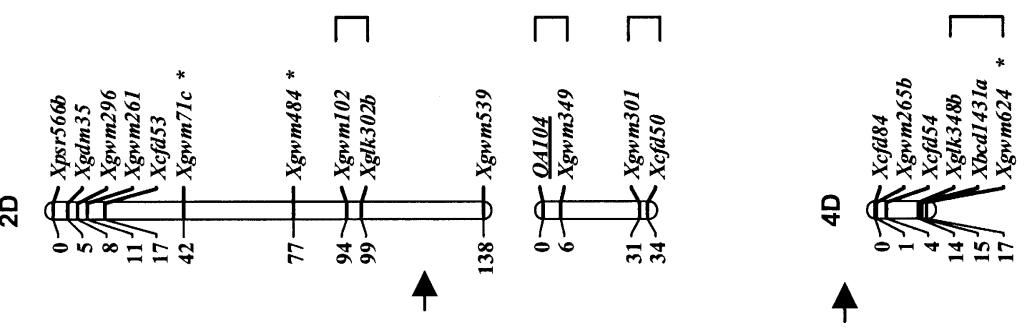

ำ

П
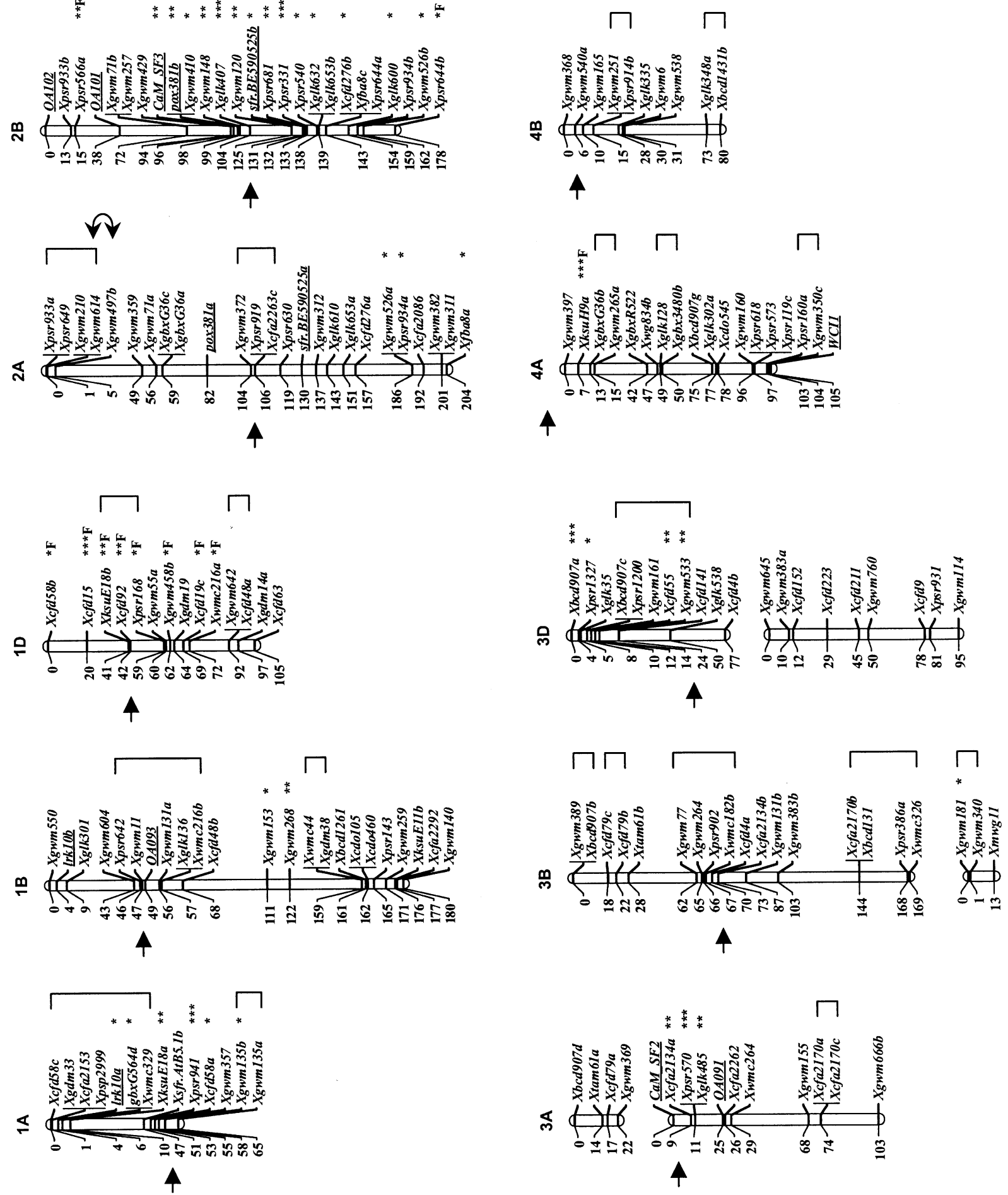

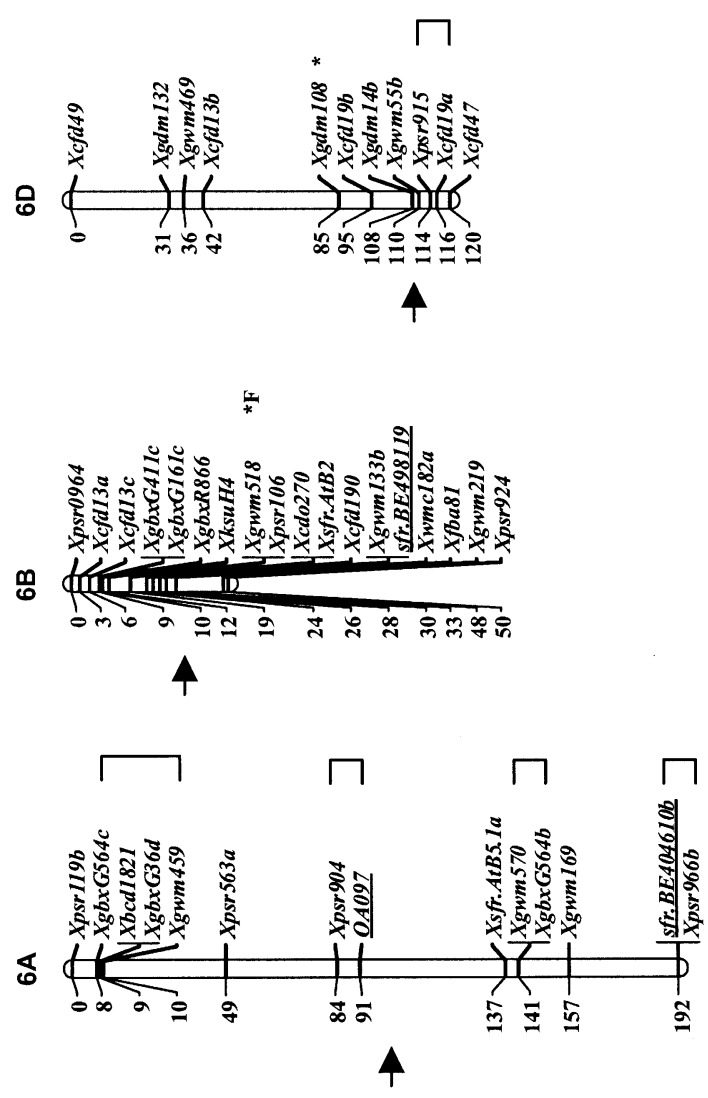
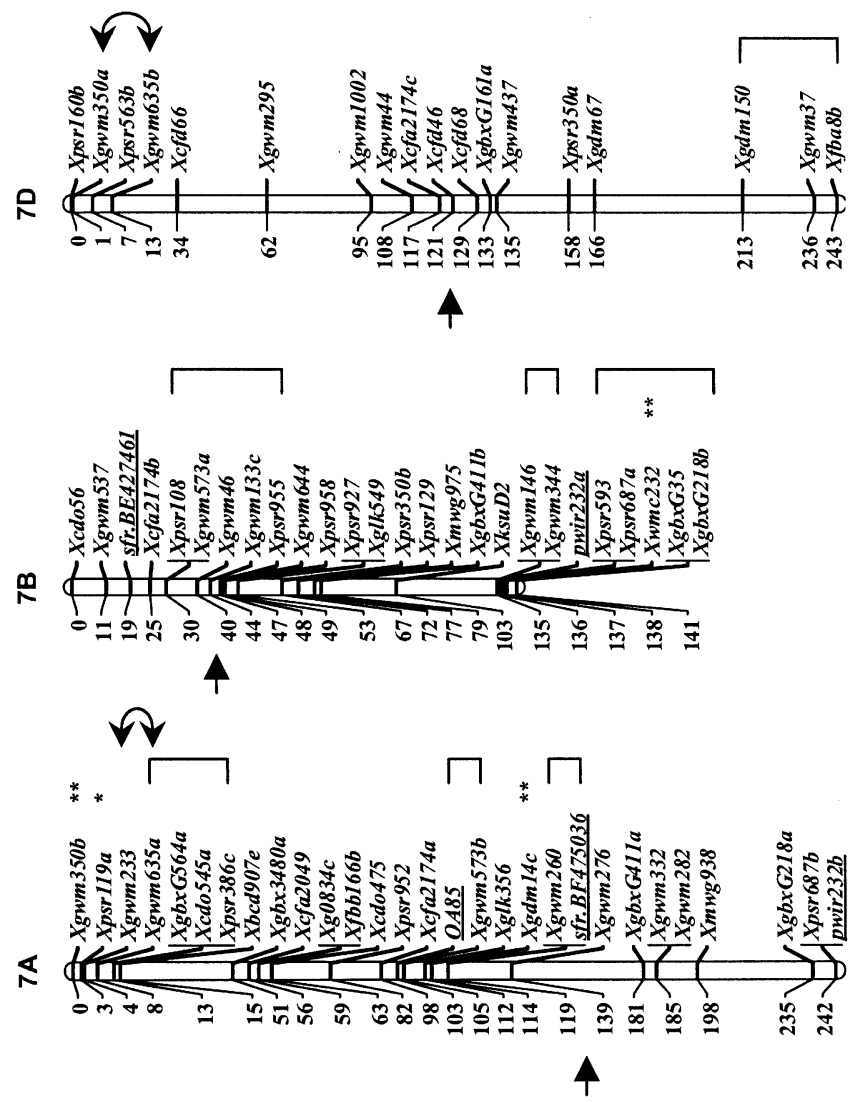

की

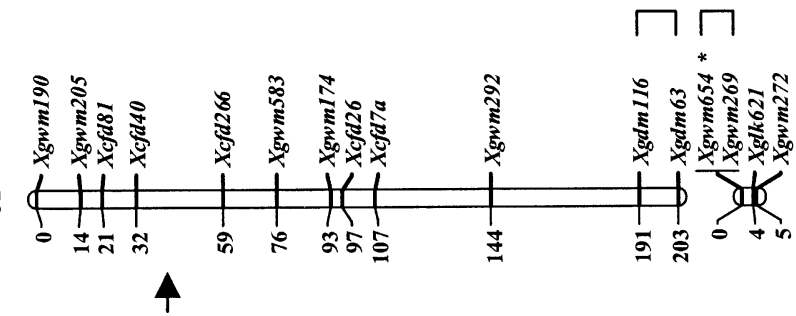

品
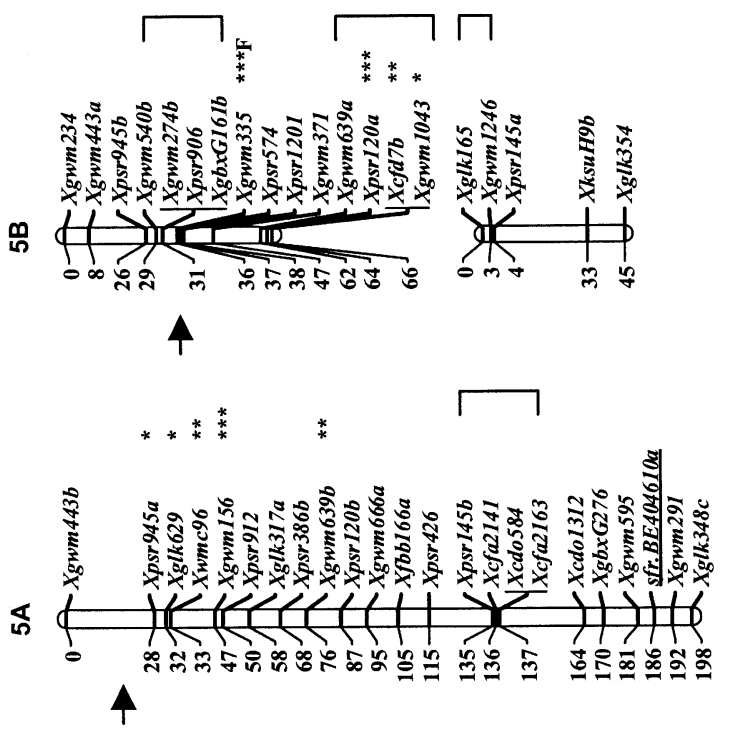

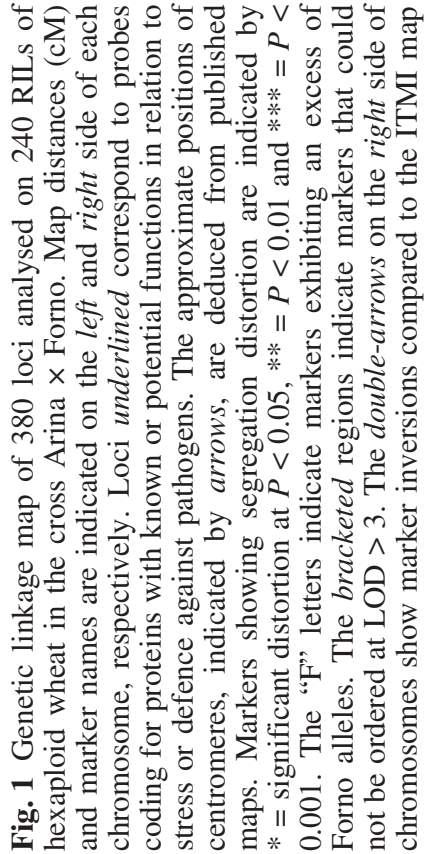


chromosome 7D with a mean of $147 \mathrm{cM} /$ chromosome. The number of loci per chromosome ranged from 6 (chromosome 4D) to 29 (chromosome 7A) with a mean of 18 loci per chromosome. Less loci were mapped on the D genome (26\%) compared to the A $(36 \%)$ or B $(38 \%)$ genomes. The global map density was 1 locus $/ 8.1 \mathrm{cM}$, with 1 locus $/ 8.2 \mathrm{cM}$ for the A genome, 1 locus $/ 6.4 \mathrm{cM}$ for the $\mathrm{B}$ genome and 1 locus $/ 10.5 \mathrm{cM}$ for the $\mathrm{D}$ genome. Although markers were carefully chosen to avoid clustering, nearly $20 \%$ of the distances were shorter or equal to $1 \mathrm{cM}$, and $54 \% \leq 5 \mathrm{cM}$. More than $50 \%$ of the markers mapped on the A $(58 \%)$ and B $(53 \%)$ genomes corresponded to RFLP, whereas $79 \%$ of the markers mapped on the $\mathrm{D}$ genome were microsatellites.

The 18 probes coding for putative stress or defencerelated proteins revealed 23 polymorphic loci on 13 chromosomes (Table 1, Fig. 1). Only one locus mapped to the D genome (chromosome 2D), whereas 12 were mapped to the A genome (all chromosomes) and 10 to the $\mathrm{B}$ genome (1B, 2B, 6B and 7B).

\section{Segregation distortion occurs in clusters}

On average, the 240 RILs inherited $51 \%$ of their alleles from the female parent Arina and $49 \%$ from the male parent Forno. This result shows that the population was skewed in favour of Arina (chi2 $=37.26, P<0.001)$. Out of the 396 markers, 67 (17\%) showed distorted segregations with similar proportions for RFLP and SSR markers (16\% and 18\%, respectively). Two marker loci (Xwg834a and $X c d o 545 c$ ) were highly distorted and removed from the data set. Their integration in the map led to strong artefactual increases of genetic distances. Dominant marker loci showed a significantly higher proportion of distortion $(24.7 \%)$ than codominant marker loci (14.1\%, chi $2=5.20, P<0.05)$. Out of the 65 remaining distorted markers, 63 were mapped and two were unlinked. Fifty (79\%) showed a segregation distortion in favour of Arina. The marker loci with distorted segregation were not randomly distributed. Thirty one were clustered in distorted regions on chromosomes 1A, 1D, 2B, 3A, 5A and 5B (Fig. 1). In these regions, except the one on 1D, all the distorted marker loci showed an excess of alleles inherited from Arina. Chromosome 2B was the most affected by segregation distortion: the observed segregation distortion region (SDR) is spanning $58 \mathrm{cM}$ and covers nearly the whole long arm and a part of the short arm.

\section{Discussion}

The genetic linkage map presented in this study is the first published intervarietal map between two winter wheat varieties. The Arina $\times$ Forno $(\mathrm{ArFo})$ map spans more than $3,000 \mathrm{cM}$, each chromosome being identified by at least one linkage group. Arina and Forno are two Swiss winter wheat varieties derived from the same breeding program.
In a former study based on RFLP analyses, Siedler et al. (1994) showed that, at the molecular level, Arina and Forno were relatively similar when compared to other European varieties. In our study, $48 \%$ of the loci were found to be polymorphic. Cadalen et al. (1997) detected $58 \%$ of polymorphism between the French variety Courtot and the variety Chinese Spring (derived from a Chinese landrace) with RFLP markers. However, despite the lower degree of polymorphism found between Arina and Forno, it was possible to build a map with a very good coverage of the genome.

In the ArFo map, similar proportions of RFLP and microsatellite markers were mapped on the A $(42 \%$ RFLP) and B (47\% RFLP) genomes. Due to the low level of polymorphism on the D genome, only 22 RFLP marker loci could be mapped on it. The low level of polymorphism in the $\mathrm{D}$ genome compared to the $\mathrm{A}$ and $\mathrm{B}$ genomes is well-known and is in agreement with the hypothesis of a recent, monophyletic introduction of the $\mathrm{D}$ genome in bread wheat (Lagudah et al. 1991). The recent isolation of microsatellite markers from Ae. tauschii (Pestsova et al. 2000; Guyomarc'h et al. 2002) has greatly facilitated the construction of saturated maps in hexaploid bread wheat.

Although we generally had a very good coverage of the map, six gaps on chromosomes 2D, 3A, 3B, 3D, 5B and 5D remained, and some chromosome arms were not or only partially covered (1AL, 4AS, 4BS, 4DL, 4DS, 6BL and 6DL). This can be explained by a lack of available markers in the corresponding regions in the reference maps (Röder et al. 1998; Messmer et al. 1999; Pestsova et al. 2000; Gupta et al. 2002; Guyomarc'h et al. 2002; Sourdille et al. 2003). The short arms of chromosomes $4 \mathrm{~A}, 4 \mathrm{~B}$ and $4 \mathrm{D}$ are not covered and the long arm of chromosome $4 \mathrm{D}$ is only $17 \mathrm{cM}$ long. In the maps published by Cadalen et al. (1997), Chalmers et al. (2001), Groos et al. (2002), Guyomarc'h et al. (2002) and Sourdille et al. (2003), chromosome 4D is either missing or only partially covered. A similar lack of coverage of group-4 chromosomes was as well-observed in some of the populations derived from intervarietal crosses.

The present map covers 3,086 cM, representing 93\% of the Synthetic W7984 × Opata 85 (ITMI) map (3,331 cM, Röder et al. 1998) and $84 \%$ of the Courtot $\times$ Chinese Spring (CtCs) intervarietal map $(3,685 \mathrm{cM}$, Sourdille et al. 2003). Common markers, mainly SSRs, allowed the comparison of intervals between our map (ArFo) and the ITMI or CtCs maps. We observed very high colinearity on 58 interval comparisons with the ITMI map and 17 with the CtCs map. Only three significant inversions were found: in the ITMI map Xgwm614-2A, Xgwm233-7A and Xgwm350-7D were distal to Xgwm4972A, Xgwm635-7A and Xgwm635-7D, respectively. Except for these inversions, the interval distances of the ArFo map were highly correlated $(P<0.0001)$ with the interval distances of the ITMI $(r=0.80)$ and $\mathrm{CtCs}(r=0.83)$ maps. The 16 intervals common to $\mathrm{ArFo}$ and $\mathrm{CtCs}$ covered $488 \mathrm{cM}$ in ArFo in comparison to $632 \mathrm{cM}$ in CtCs. Twelve intervals were shorter in ArFo than in CtCs. In contrast, the comparison of ArFo and ITMI map-intervals 
did not show differences, with a total of $1,958 \mathrm{cM}$ and $1,939 \mathrm{cM}$ respectively for the 55 intervals considered. Twenty nine intervals were shorter in the ArFo map than in the ITMI map. These results show that our map is consistent with other published maps.

The distortion found on chromosome 2B was observed in many studies (Cadalen et al. 1997; Campbell et al. 1999; Kammholz et al. 2001; Groos et al. 2002) and corresponds to the same large region on CtCs. In the RIL progeny, this distortion cannot be attributed to androgenesis ability as suggested for the doubled-haploid progeny of Cadalen et al. (1997). The existence of markers or chromosomic regions showing segregation distortions has already been reported in other plant species (see Jenczewski et al. 1997 and Xu et al. 1997 for reviews). In rice and maize, some segregation distortion regions (SDR) were detected close to the location of known gametophytic factors (Xu et al. 1997; Lu et al. 2002). To our knowledge, no study on gametophytic factors of wheat has been published yet. The segregation distortion found for chromosome $2 \mathrm{~B}$ in different populations suggests the involvement of a genetic factor (gametophytic or else) and should be further investigated. In addition to mapping discrepancies, distortion segregation can also constitute a handicap by lowering the rate of recombinants between loci of interest.

It is of high interest that for the ArFo map, RFLP and microsatellite markers from more than ten different maps (SSRs: Röder et al. 1998; Pestsova et al. 2000; Gupta et al. 2002; Guyomarc'h et al. 2002; Sourdille et al. 2003; RFLPs: Liu and Tsunewaki 1991; Mingeot and Jacquemin 1999; ITMI maps on grain-genes database, http:// wheat.pw.usda.gov/index.shtml) have been integrated on the same population and in the same laboratory. This will facilitate future mapping studies. This map has already enabled the QTL mapping of several disease resistance genes: Stagonospora glume blotch (Schnurbusch et al. 2003), leaf rust and Fusarium head blight (our unpublished results) and could be used for the study of other disease resistances as well as quality traits.

Acknowledgements We thank Dr. M. Gale (John Innes Centre, Norwich, UK), Dr. M. Röder, Dr. A. Graner and Dr. N. Stein (IPK Gatersleben, Germany), C. Wilson (USDA-ARS, Albany Calif., USA), Dr. R. Dudler (University of Zürich, Switzerland), Dr. H. Fromm (University of Leeds, UK), Dr. P. Bailey (John Innes Centre, Norwich, UK), Dr. O. Anderson (Albany Calif., USA) and TraitGenetics Inc. (Gatersleben, Germany) for providing clones, unpublished primer sequences or mapping informations. The authors thank Dr. C. Feuillet (University of Zürich, Switzerland) for critical reading of the manuscript. Dr. L. Moreau (INRA Le Moulon, Gif-sur-Yvette, France) is acknowledged for her advice in using Mapmaker. Funding for this work was provided by the IndoSwiss Collaboration in Biotechnology and grant 3100-065114 from the Swiss National Science Foundation. All experiments conducted during this study comply with current Swiss laws.

\section{References}

Bryan GJ, Collins AJ, Stephenson P, Orry A, Smith JB, Gale MD (1997) Isolation and characterisation of microsatellites from hexaploid bread wheat. Theor Appl Genet 94:557-563

Cadalen T, Boeuf C, Bernard S, Bernard M (1997) An intervarietal molecular marker map in Triticum aestivum $\mathrm{L}$ em Thell and comparison with a map from a wide cross. Theor Appl Genet 94:367-377

Campbell KG, Bergman CJ, Gualberto DG, Anderson JA, Giroux MJ, Hareland G, Fulcher RG, Sorrells ME, Finney PL (1999) Quantitative trait loci associated with kernel traits in a soft $\times$ hard wheat cross. Crop Sci 39:1184-1195

Chalmers KJ, Campbell AW, Kretschmer J, Karakousis A, Henschke PH, Pierens S, Harker N, Pallotta M, Cornish GB, Shariflou MR, Rampling LR, McLauchlan A, Daggard G, Sharp PJ, Holton TA, Sutherland MW, Appels R, Langridge P (2001) Construction of three linkage maps in bread wheat, Triticum aestivum. Aust J Agric Res 52:1089-1119

Chao S, Sharp PJ, Worland AJ, Warham EJ, Koebner RMD, Gale MD (1989) RFLP-based genetic maps of wheat homoeologous group-7 chromosomes. Theor Appl Genet 78:495-504

Clough SJ, Fengler KA, Yu IC, Lippok B, Smith RK, Bent AF (2000) The Arabidopsis dndl "defense, no death" gene encodes a mutated cyclic nucleotide-gated ion channel. Proc Natl Acad Sci USA 97:9323-9328

Devey ME, Hart GE (1993) Chromosomal localization of intergenomic RFLP loci in hexaploid wheat. Genome 36:913-918

Feuillet C, Schachermayr G, Keller B (1997) Molecular cloning of a new receptor-like kinase gene encoded at the Lr10 disease resistance locus of wheat. Plant J 11:45-52

Gale MD, Atkinson MD, Chinoy CN, Harcourt RL, Liu J, Li QY, DK M (1995) Genetic maps of hexaploid wheat. In: Li ZS, Xin ZY (eds) Proc 8th Int Wheat Genet Symp, Agric Scientech Press, Beijing, pp 29-40

Gill KS, Lubbers EL, Gill BS, Raupp WJ, Cox TS (1991) A genetic-linkage map of Triticum tauschii (DD) and its relationship to the D-genome of bread wheat (AABBDD). Genome 34:362-374

Gorlach J, Volrath S, KnaufBeiter G, Hengy G, Beckhove U, Kogel KH, Oostendorp M, Staub T, Ward E, Kessmann H, Ryals J (1996) Benzothiadiazole, a novel class of inducers of systemic acquired resistance, activates gene expression and disease resistance in wheat. Plant Cell 8:629-643

Graner A, Jahoor A, Schondelmaier J, Siedler H, Pillen K, Fischbeck G, Wenzel G, Herrmann RG (1991) Construction of an RFLP map of barley. Theor Appl Genet 83:250-256

Groos C, Gay G, Perretant MR, Gervais L, Bernard M, Dedryver F, Charmet D (2002) Study of the relationship between preharvest sprouting and grain color by quantitative trait loci analysis in a white $\times$ red grain bread-wheat cross. Theor Appl Genet 104:39-47

Gupta PK, Balyan HS, Edwards KJ, Isaac P, Korzun V, Röder M, Gautier MF, Joudrier P, Schlatter AR, Dubcovsky J, De la Pena RC, Khairallah M, Penner G, Hayden MJ, Sharp P, Keller B, Wang RCC, Hardouin JP, Jack P, Leroy P (2002) Genetic mapping of 66 new microsatellite (SSR) loci in bread wheat. Theor Appl Genet 105:413-422

Guyomarc'h H, Sourdille P, Edwards KJ, Bernard M (2002) Studies of the transferability of microsatellites derived from Triticum tauschii to hexaploid wheat and to diploid related species using amplification, hybridization and sequence comparisons. Theor Appl Genet 105:736-744

Haldane JBS (1919) The combination of linkage values, and the calculation of distance between loci of linked factors. J Genet 8:299-309

Harding SA, Oh SH, Roberts DM (1997) Transgenic tobacco expressing a foreign calmodulin gene shows an enhanced production of active oxygen species. EMBO J 16:1137-1144

Heun M, Kennedy AE, Anderson JA, Lapitan NLV, Sorrells ME, Tanksley SD (1991) Construction of a restriction fragment 
length polymorphism map for barley (Hordeum vulgare). Genome 34:437-447

Hirschi KD (1999) Expression of Arabidopsis CAX1 in tobacco: altered calcium homeostasis and increased stress sensitivity. Plant Cell 11:2113-2122

Jenczewski E, Gherardi M, Bonnin I, Prosperi JM, Olivieri I, Huguet T (1997) Insight on segregation distortions in two intraspecific crosses between annual species of Medicago (Leguminosae). Theor Appl Genet 94:682-691

Kammholz SJ, Campbell AW, Sutherland MW, Hollamby GJ, Martin PJ, Eastwood RF, Barclay I, Wilson RE, Brennan PS, Sheppard JA (2001) Establishment and characterisation of wheat genetic mapping populations. Aust J Agric Res 52:1079_ 1088

Lagudah ES, Appels R, Brown AHD, McNeil D (1991) The molecular-genetic analysis of Triticum tauschii, the D-genome donor to hexaploid wheat. Genome 34:375-386

Lander ES, Green P, Abrahamson J, Barlow A, Daly MJ, Lincoln SE, Newburg L (1987) MAPMAKER: an interactive computer package for constructing primary genetic linkage maps of experimental and natural populations. Genomics 1:174-181

Leroy P (1995) Le catalogue des clones Génoblé. Publisher: Ministére de l'Agriculture, INRA, Université de Paris Sud, GIS Génoblé

Liu Y, Tsunewaki K (1991) Restriction fragment length polymorphism (RFLP) in wheat II. Linkage maps of the RFLP sites in common wheat. Jpn J Genet 66:617-633

Liu YG, Mori N, Tsunewaki K (1990) Restriction fragment length polymorphism (RFLP) analysis in wheat I. Genomic DNA library construction and RFLP analysis in common wheat. Jpn J Genet 65:367-380

Lu H, Romero-Severson J, Bernardo R (2002) Chromosomal regions associated with segregation distortion in maize. Theor Appl Genet 105:622-628

Maeshima M (2000) Vacuolar $\mathrm{H}^{+}$-pyrophosphatase. Biochim Biophys Acta-Biomembr 1465:37-5

Messmer MM, Keller M, Zanetti S, Keller B (1999) Genetic linkage map of a wheat $\times$ spelt cross. Theor Appl Genet 98:1163-1170

Mingeot D, Jacquemin JM (1999) Mapping of RFLP probes characterized for their polymorphism on wheat. Theor Appl Genet 98:1132-1137

Pestsova E, Ganal MW, Röder MS (2000) Isolation and mapping of microsatellite markers specific for the D genome of bread wheat. Genome 43:689-697

Plaschke J, Ganal MW, Röder MS (1995) Detection of genetic diversity in closely related bread wheat using microsatellite markers. Theor Appl Genet 91:1001-1007
Rebmann G, Hertig C, Bull J, Mauch F, Dudler R (1991a) Cloning and sequencing of cDNAs encoding a pathogen-induced putative peroxidase of wheat (Triticum aestivum L). Plant Mol Biol 16:329-331

Rebmann G, Mauch F, Dudler R (1991b) Sequence of a wheat cDNA-encoding a pathogen-induced thaumatin- like protein. Plant Mol Biol 17:283-285

Röder MS, Korzun V, Wendehake K, Plaschke J, Tixier MH, Leroy P, Ganal MW (1998) A microsatellite map of wheat. Genetics 149:2007-2023

Romeis T, Ludwig AA, Martin R, Jones JDG (2001) Calciumdependent protein kinases play an essential role in a plant defence response. EMBO J 20:5556-5567

Sagi M, Fluhr R (2001) Superoxide production by plant homologues of the gp91(phox) NADPH oxidase. Modulation of activity by calcium and by tobacco mosaic virus infection. Plant Physiol 126:1281-1290

Schnurbusch T, Paillard S, Fossati D, Messmer M, Schachermayr G, Winzeler M, Keller B (2003) Dissecting quantitative and durable Stagonospora glume blotch resistance in Swiss winter wheat. Theor Appl Genet (in press)

Sears ER (1966) Chromosome mapping with the aid of telocentrics. In: MacKey J (ed) 2nd Wheat Genet Symp, Lund, pp 370-381

Siedler H, Messmer MM, Schachermayr GM, Winzeler H, Winzeler M, Keller B (1994) Genetic diversity in European wheat and spelt breeding material based on RFLP data. Theor Appl Genet 88:994-1003

Sourdille P, Cadalen T, Guyomarc'h H, Snape JW, Perretant MR, Charmet G, Boeuf C, Bernard S, Bernard M (2003) An update of the Courtot $\times$ Chinese Spring intervarietal molecular marker linkage map for the QTL detection of agronomic traits in wheat. Theor Appl Genet 106:530-538

Voorips RE (2002) Mapchart: software for the graphical presentation of linkage maps and QTLs. J Hered 93:77-78

Xu Y, Zhu L, Xiao J, Huang N, McCouch SR (1997) Chromosomal regions associated with segregation distortion of molecular markers in $\mathrm{F}_{2}$, backcross, doubled-haploid, and recombinant inbred populations in rice (Oryza sativa L.). Mol Gen Genet 253:535-545

Yang TB, Segal G, Abbo S, Feldman M, Fromm H (1996) Characterization of the calmodulin gene family in wheat: structure, chromosomal location, and evolutionary aspects. Mol Gen Genet 252:684-694

Young ND, Tanksley SD (1989) Restriction fragment length polymorphism maps and the concept of graphical genotypes. Theor Appl Genet 77:95-101 